\title{
Endoscopic coloenterostomy for treatment of malignant small-bowel obstruction: troubleshooting and management of complications
}

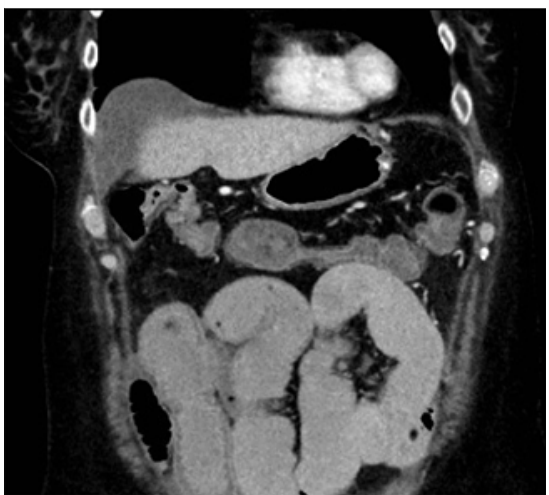

$>$ Fig. 1 Initial computed tomography scan revealing a small-bowel obstruction with multiple dilated small-bowel loops with a transition point at the distal ileal loop.

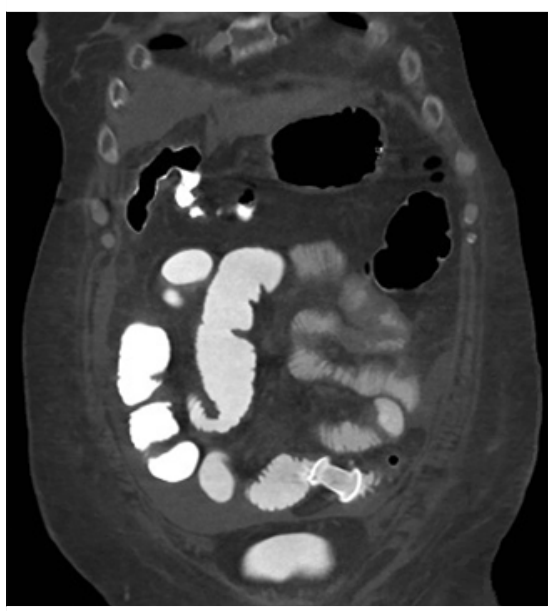

- Fig. 2 Final computed tomography scan with lumen-apposing metal stent in place.

A 66-year-old woman with a past medical history of metastatic pancreatic cancer with peritoneal carcinomatosis presented to the hospital with 1-week history of worsening abdominal pain, distension, nausea, and vomiting. Computed tomography $(\mathrm{CT})$ revealed a malignant-appearing thickening of the small bowel, causing obstruction with a transition point at the distal ileal loop ( $\triangleright$ Fig. 1). A nasogastric tube was placed on low intermittent

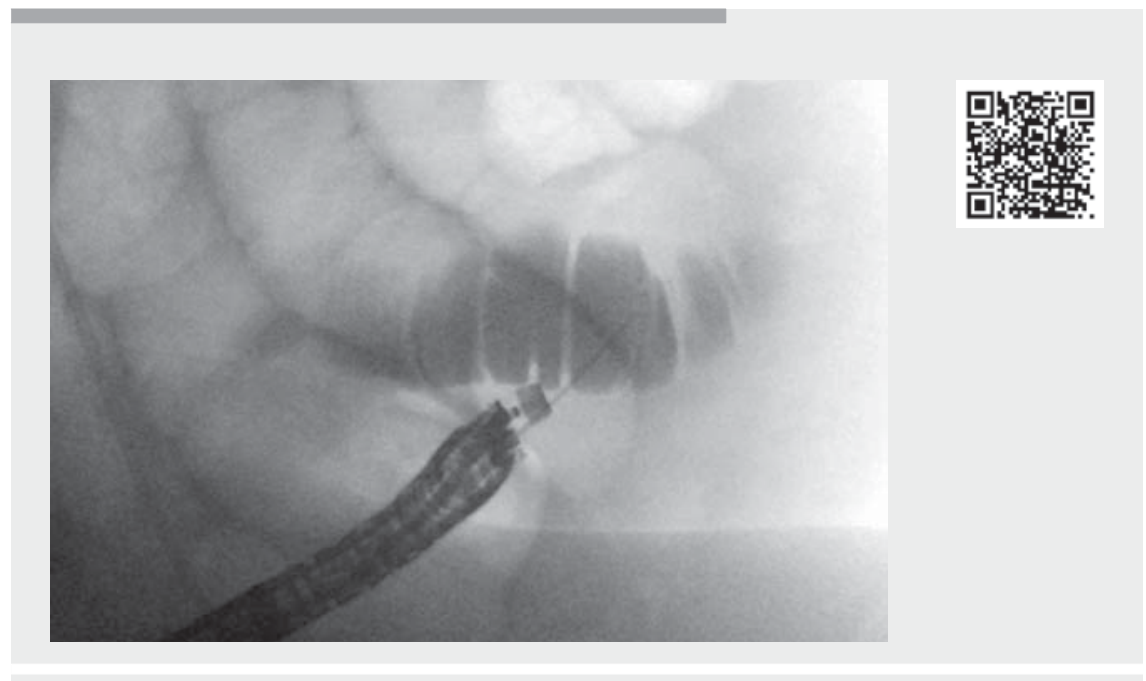

Video 1 Placement of coloenteric stent and management of complications.

suction for immediate symptomatic treatment. The patient was deemed a poor surgical candidate due to extensive metastatic disease, however she was willing to pursue further options to resolve her small-bowel obstruction and ultimately resume chemotherapy. Therefore, upon multidisciplinary agreement and patient consent, we decided to proceed with an attempt for an endoscopic ultrasound (EUS)-guided coloenterostomy, bypassing the malignant smallbowel obstruction.

After careful maneuvering through the sigmoid colon using a ball tip cannula and guidewire, the EUS endoscope was approximated to dilated small-bowel loops, guided by fluoroscopy (Video image, Video 1). Injection of contrast through a 22-gauge biopsy needle confirmed a small-bowel loop adjacent to the sigmoid colon, which was further distended by injection of saline. A cautery-tipped lumen-apposing stent (Hot AXIOS; Boston Scientific, Marlborough, Massachusetts, USA) was used to puncture the small bowel; however the stent deployed at the external wall of the small bowel with its distal flange in the perito- neum. Percutaneous decompression was performed. Then, an EUS biopsy needle was used to secure the stent by threading a guidewire through its lumen. A second stent was deployed through a guidewire, with its proximal flange within the colon and distal flange bridging the other stent. The displaced stent was retrieved with forceps and the perforation closed with clips. The patient required antibiotics, antifungals, and paracentesis to remove leaked colonic contents, with postprocedural improvement and resolution of symptoms within days. A follow-up CT scan revealed the passage of contrast through the coloenterostomy stent anastomosis, with absence of a leak ( $>$ Fig. 2). Small-bowel obstruction secondary to malignant disease is a sign of advanced primary malignancy associated with poor survival and quality of life [1]. It is the most common site of obstruction of the gastrointestinal tract caused by malignancy [2]. Despite the superiority of operative treatment over conservative management, $>50 \%$ of patients managed operatively have a recurrence, and $>60 \%$ of these patients have postoperative morbidity [1]. Therefore, the need 
for less invasive alternatives to palliatively manage small-bowel obstruction is a potential opportunity for an endoscopic attempt to relieve the obstruction. The successful use of a lumen-apposing metal stent (LAMS) to treat small-bowel obstruction by performing a coloenteric anastomosis was recently reported [3, 4]. We present the first video description of coloenteric anastomosis with an explanation of potential complications (including perforation) and their immediate treatment.

Endoscopy_UCTN_Code_CPL_1AL_2AG

\section{Competing interests}

Avik Sarkar has done consulting work for US Endoscopy and Obalon Therapeutics. Haroon Shahid has done consulting work for US Endoscopy. Amy Tyberg has done consulting work for NinePoint Medical, EndoGastric Solutions, and Obalon Therapeutics. Michel Kahaleh has done consulting work for Boston Scientific, Interscope Med, and Abbvie. He has received research grants from Boston Scientific, Emcision, Conmed, Pinnacle, Cook, Gore, Merit, and Olympus.
The authors

Mihajlo Gjeorgjievski ${ }^{\circ}$, Abdelhai Abdelqader, Avik Sarkar, Haroon Shahid, Amy Tyberg,

\section{Michel Kahaleh ${ }^{\circ}$}

Department of Gastroenterology and Hepatology, Robert Wood Johnson University

Hospital, New Brunswick, New Jersey, USA

\section{Corresponding author}

\section{Michel Kahaleh, MD}

Department of Gastroenterology, Robert Wood Johnson University Hospital, 1 RWJ Place, MEB 464, New Brunswick, NJ 08901, United States

Fax: +1-732-235-7307

mkahaleh@gmail.com

\section{References}

[1] Miller G, Boman J, Shrier I et al. Small-bowel obstruction secondary to malignant disease: an 11-year audit. Can J Surg 2000; 43: 353358

[2] Pujara D, Chiang Y-J, Cormier JN et al. Selective approach for patients with advanced malignancy and gastrointestinal obstruction. J Am Coll Surg 2017; 225: 53-59

[3] Mai HD, Dubin E, Mavanur AA et al. EUSguided colo-enterostomy as a salvage drainage procedure in a high surgical risk patient with small bowel obstruction due to severe ileocolonic anastomotic stricture: a new application of lumen-apposing metal stent (LAMS). Clin J Gastroenterol 2018; 11 : 282-285
[4] Mir A, Parekh PJ, Shakhatreh M et al. Endoscopic ultrasound-guided creation of an enterocolostomy to relieve malignant bowel obstruction. Endosc Int Open 2019; 7: E1034-E1037

Bibliography

Endoscopy 2022; 54: E176-E177

DOI 10.1055/a-1463-2495

ISSN 0013-726X

published online 28.4.2021

(c) 2021. Thieme. All rights reserved. Georg Thieme Verlag KG, Rüdigerstraße 14, 70469 Stuttgart, Germany

\section{ENDOSCOPY E-VIDEOS}

https:|/eref.thieme.de/e-videos

回店 Endoscopy E-Videos is an open access online section, 靣舴: reporting on interesting cases and new techniques in gastroenterological endoscopy. All papers include a high quality video and all contributions are freely accessible online. Processing charges apply (currently EUR 375), discounts and wavers acc. to HINARI are available.

This section has its own submission website at https://mc.manuscriptcentral.com/e-videos 